\title{
MANEJ O SUSTENTADO DA FERTILIDADE DE UM LATOSSOLO DA AMAZÔNIA CENTRAL SOB CULTIVOS SUCESSIVOS ${ }^{(1)}$
}

\author{
M. S. CRAVO(2) \& T. J . SMYTH ${ }^{(3)}$
}

\begin{abstract}
RESUMO
Estimativas da área desmatada na Amazônia brasi leira, principalmente para a pecuária e agricultura itinerante, já ultrapassam o equivalente à superfície do Estado de Rondônia. Com objetivo de estabelecer o modelo de exaustão de nutrientes do solo e determinar as necessidades de fertilizantes e de calcário para o cultivo sucessivo, após desmatamento e queima da vegetação, foi instalado um experimento em um latossolo amarelo próximo de Manaus (AM). Foram avaliadas respostas às aplicações de N, P, K, Mg, S, B, Cu, Mn, Zn e calcário, durante oito anos de cultivo. No período de 1981 a 1990, foram feitos 17 cultivos, observando-se respostas ao $P, K$, calcário e Mg, a partir do primeiro, segundo, terceiro e décimo primeiro cultivos, respectivamente. Para N, só houve resposta nos cultivos de milho, sen do necessário aumentar as aplicações a cada culti vo. Na ausência de adu bação e de calagem, houve redução dos teores de $\mathrm{N}, \mathrm{P}, \mathrm{K}, \mathrm{Ca}, \mathrm{Mg}, \mathrm{C}$ e do pH e aumento da saturação de Al, com o tempo de cultivo. $\mathrm{O}$ uso de fertilizantes e de calcário, com base na análise do solo, permitiu o cultivo contínuo da mesma área, com uma produtividade média de

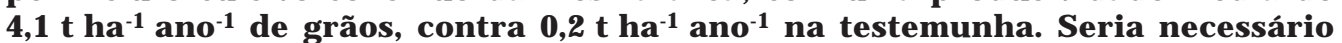
cultivar, aproximadamente, 24 ha no sistema itinerante, para se conseguir o total de grãos produzidos em 1 ha, durante oito anos, com manejo adequado de fertilizantes e de calcário.
\end{abstract}

Termos de indexação: trópico úmido, latossolo amarelo, desflorestamento, agricultura itinerante, agricultura sustentada.

\section{SUMMARY:SOIL FERTILITY MANAGEMENT FOR SUSTAINABLE CROPPING ON AN OXISOL OF THE CENTRAL AMAZON}

Estimates of deforestation in theBrazilian Amazon, primarily for shifting cultivation and pastures, exceed the land area for the State of Rondônia. An experiment was conducted on a Xanthic Hapludox near Manaus, Brazil to establish soil nutrient depl etion patterns and fertilizer and limerequi rements for conti nuous cultivation after slash-and-burn clearing. Yield responses

\footnotetext{
(1) Parte do trabal ho apresentado na XX Reunião Brasileira de Fertilidade do Solo e Nutrição de Plantas, Piracicaba, 1992 e na XXII Reunião Brasileira de Fertilidade do Solo e Nutrição de Plantas, Manaus, 1996. Pesquisa desenvolvida por intermédio do convênio EMBRAPA-CPAA/N orth Carolina State University (USA). Recebido para publicação em fevereiro e aprovado em setembro de 1997.

(2) Pesquisador da EMBRAPA/CPAA, Caixa Postal 319, CEP 69011-970 Manaus (AM).

(3) Professor do Departamento de Ciência do Solo da Universidade Estadual de Carolina do Norte (USA), Raleigh, NC 27695-7619.
} 
to $\mathrm{N}, \mathrm{P}, \mathrm{K}, \mathrm{Mg}, \mathrm{S}, \mathrm{B}, \mathrm{Cu}, \mathrm{Mn}, \mathrm{Zn}$ and lime were evaluated during eight years of cultivation. Seventeen crops were grown during the period from 1981 to 1990, and yield responses were detected for $\mathrm{P}, \mathrm{K}$, limeand $\mathrm{M}$ g beginning with thefirst, second, third and 11 th crops, respectively. Only corn crops responded to $\mathrm{N}$ and therequirements increased with each crop. In theabsence of fertilizer and limesoil N, P, K, Ca, Mg, C and pH decreased and percent Al saturation increased with time of cultivation. Mean crop yields, with liming and fertilization based on soil analyses, were $4.1 \mathrm{t} \mathrm{ha}^{-1} \mathrm{yr}^{-1}$ as opposed to $0.2 \mathrm{t} \mathrm{ha}^{-1} \mathrm{yr}^{-1}$ in thecheck treatment. Total grain yiel ds obtained from 1 ha, during eight years with adequatefertilizer and limemanagement, would correspond to yields from 24 ha of land under shifting cultivation practices.

Index terms: humid tropics, Oxi sol, deforestation, shifting cultivation, sustainableagriculture

\section{INTRODUÇÃO}

A Amazônia brasileira vem sofrendo acelerado processo de ocupação, causando intenso corte de suas florestas. Fearnside (1990) estima que a área desmatada corresponde a $7 \%$ da região, enquanto, para Cunha (1989), ela representa 5,12\% da Amazônia Legal, correspondendo a mais de $250.000 \mathrm{~km}^{2}$. Por mais modesta que seja a estimativa, a área desmatada é maior que a superfície do Estado de Rondônia. De acordo com Mahar (1989), as principais causas do desmatamento são a agricultura de pequena escala, a formação de pastagens, a expl oração madeireira, as construções de estradas e de hidroelétricas, as atividades de mineração e o crescimento urbano, das quais as duas primeiras são as que mais contribuem para o processo.

A não utilização de adubos ecorretivos acarreta um dos principais problemas enfrentados pelos agricultores da Amazônia - a baixa produtividade, obtida a partir do segundo cultivo após a queima da vegetação florestal. Cultivos na mesma gl eba se restringem aos dois primeiros anos, tempo em que os efeitos fertilizantes e corretivos das cinzas ainda permitem col heitas razoáveis. É o que se conhece como sistema de agricultura itinerante. Estudos realizados por Smyth \& Bastos (1984), em Manaus, mostraram sensível mel hora nas características químicas do solo pelas cinzas, porém, de curta duração.

No ecossistema de terra firme na Amazônia, predominam os latossolos amarelos e os podzólicos vermel ho-amarel os, sol os altamente intemperizados, com características físicas adequadas ao uso agrícola, mas com fortes limitações nutricionais (Radambrasil, 1975). O P é considerado o el emento mais limitante ao crescimento das culturas, sendo deficienteem $90 \%$ dos solos da região, seguido pelo $\mathrm{N}$ e pelo K. Além disso, $70 \%$ dos sol os da região amazônica são ácidos e apresentam toxicidade causada pel o Al (Cochrane \& Sanchez, 1982). E ntretanto, quando essas limitações de natureza química são superadas pela aplicação de cal cário edenutrientes, as produtividades das culturas passam a ser equival entes às obtidas em outros solos, quimicamente, mel hores (Sanchez \& Salinas, 1981).

Para o cultivo contínuo desses solos, como opção para diminuir a taxa de desflorestamento, torna-se necessário definir as exigências nutricionais das culturas, bem como a seqüência de ocorrência de deficiências nutricionais durante o período de utilização da terra. Estudos dessa natureza foram feitos em podzólicos na Amazônia peruana por Sanchez et al. (1983). Após o primeiro cultivo, esses pesquisadores observaram não só decréscimos no pH e nos teores de $\mathrm{Ca}, \mathrm{Mg}, \mathrm{N}, \mathrm{K}, \mathrm{P}, \mathrm{Cu}$ e $\mathrm{Mn}$ no solo, mas também aumento da saturação de Al. A correção dessas deficiências durante 21 cultivos de arroz, milho e soja permitiu manter uma produtividade média de 2,7 t ha-1 de grãos, enquanto a testemunha apresentou produtividade média de 0,5 t ha-1 cultivo-1.

Os objetivos deste trabalho foram: estabelecer o model o de exaustão de nutrientes de um latossolo da Amazônia central brasileira com o tempo após o desmatamento e queima da vegetação; e, determinar a necessi dade de nutrientes ede cal cário para o cultivo contínuo e sustentado desse solo.

\section{MATERIAL E MÉTODOS}

O trabalho foi iniciado em 1981, na Estação Experimental da EMBRAPA-Centro de Pesquisa Agroflorestal da Amazônia Ocidental (CPAA), situada $30 \mathrm{~km}$ ao Norte de Manaus (AM) ( $3^{\circ} 8^{\prime}$ de latitude sul e $59^{\circ} 52^{\prime}$ de longitude oeste, com $50 \mathrm{~m}$ de altitude). As médias das temperaturas máximas e mínimas mensais são de 32 e $22^{\circ} \mathrm{C}$, respectivamente. A precipitação média anual é de $2.420 \mathrm{~mm}$, com um máximo de $295 \mathrm{~mm}$ mensais, em março e em abril, e um mínimo de $105 \mathrm{~mm}$ mensais, em agosto e em setembro (EMBRAPA, 1984). O solo foi classificado como latossolo amarel oálico muito argil loso (Rodrigues et al., 1972). As características químicas iniciais do solo $(0-20 \mathrm{~cm})$ eram: $\mathrm{pH}$ em água $=4,2 ; \mathrm{CTC}$ efetiva $=$ $23 \mathrm{mmol}_{\mathrm{c}} \mathrm{dm}^{-3} ; \mathrm{P}, \mathrm{K}, \mathrm{Fe}, \mathrm{Mn}$ e $\mathrm{Zn}$ extraídos com Mehlich-1 =2; 22; 175; 2 e $1 \mathrm{mg} \mathrm{dm}^{-3}$, respectivamente; e saturação de $\mathrm{Al}=78 \%$ (Smyth \& Bastos, 1984). A vegetação da área, que era de floresta equatorial úmida, foi derrubada manualmenteequeimada, tendo sido removidos da área os troncos não queimados. Após a destoca, a área foi arada e gradeada para o primeiro plantio e para os plantios subseqüentes, preparada com enxada rotativa a uma profundidade de $15 \mathrm{~cm}$.

Sanchez et al. (1983) analisando, em um podzólico da Amazônia peruana, orendimento de cultivos entre dois tratamentos - uma testemunha absoluta e outro constituído pel o ajuste de uma adubação completa com 
basena análisedesoloanterior a cada cultivo- encontraram dificuldade em avaliar o comportamento individual dos el ementos testados.

Neste trabalho, optou-se por determinar a contribuição de cada nutriente à produtividade, ao longo do período de cultivo. Para isso, foi necessário estabel ecer um experimento que permitisse antecipar uma eventual resposta das culturas a cada nutriente ecal cário, a partir do momento em que se identificasse deficiência/toxicidade do el emento. O experimento constituiu-se de 35 tratamentos, visando avaliar três ou quatro doses de N, P, K, Mg, S, B, Cu, Mn, Zn e de cal cário, al ém de uma testemunha absol uta. As doses, fontes, freqüência de aplicações eépoca na qual foram iniciadas as aval iações de cada nutriente e do calcário encontram-se no quadro 1 . Incluiu-se o tratamento denominado "resíduos", para avaliar o efeito da remoção de restos vegetais nas colheitas de cada cultivo de arroz e de soja. Nesses cultivos, os restos vegetais foram retornados somente às parcelas do tratamento "resíduos", após a trilha dos grãos. Nos cultivos de caupi e milho, os restos vegetais foram mantidos em todos os tratamentos. Com exceção de N, P, testemunha e o tratamento "resíduos", o início da aplicação do tratamento, para cada nutriente ou calcário, foi baseado na análise de solo do cultivo anterior. Ao verificar possível deficiência de um nutriente, iniciava-se sua correção para o cultivo subseqüente e, se confirmada a resposta, aplicava-se o nutriente em uma dose básica nos demais tratamentos (exceto na testemunha e no tratamento "resíduos") antes do cultivo subseqüente. Procurouse, assim, evitar confusão entre respostas a um elemento, com deficiência de outros.

Após o 3o cultivo com soja, que foi o 80 cultivo do experimento, o tratamento "resíduos" foi usado para avaliar o efeito da não aplicação do fertilizante potássico $\left(\mathrm{K}_{0}\right)$ nos nove cultivos finais.

O N só foi aplicado para o milho e arroz, com as doses parceladas em três aplicações iguais (no plantio, aos 25 e 55 dias do plantio). A primeira aplicação foi feita a lanço e incorporada com enxada rotativa, e as duas últimas, ao longo das linhas de plantio e incorporadas, manualmente, com enxada, durante o período de capina. Os demais nutrientes e o cal cário foram aplicados a lanço, antes do plantio, eincorporados com enxada rotativa. Em alguns plantios de soja e de caupi, foi feita a aplicação de mol ibdato de amônio na dosagem de $20 \mathrm{~g} \mathrm{ha}^{-1}$ deMo, em mistura comas sementes.

As espécies utilizadas nos 17 cultivos sucessivos foram milho (Zea mays), soja (Glycine max (L.) Merrill), arroz (Oryza sativa) e caupi (Vigna unguiculata (L.) Walp), com densidades de 55.000, 200.000, 550.000 e 200.000 plantas ha-1, respectivamente. O período de plantio do milho e arroz variou

\section{Quadro 1. Doses, fontes, freqüência de aplicação e número do cultivo relativo ao início de cada tratamento para avaliar os efeitos de nutrientes, calcário e manejo de restos culturais em um latossolo amarelo de Manaus (AM)}

\begin{tabular}{|c|c|c|}
\hline Tratamento & Início ${ }^{(1)}$ & Fonte \\
\hline & $\mathrm{n}$ - do cultivo & \\
\hline Testemunha & 1 & - \\
\hline $\mathrm{N}$ & 1 & Uréia \\
\hline$P$ & 1 & Superfosfato triplo \\
\hline Resíduos $^{(3)}$ & 2 & - \\
\hline K & 2 & $\mathrm{KCl}$ \\
\hline $\mathrm{Cu}$ & 3 & Sulfato de cobre \\
\hline Calcário & 3 & $\begin{array}{l}47,2 \% \text { de } \mathrm{CaO}, 0,96 \% \text { de } \mathrm{MgO}, 84,4 \% \text { de } \\
\text { reatividade }\end{array}$ \\
\hline $\mathrm{S}$ & 5 & Sulfato de amônio \\
\hline B & 7 & Bórax \\
\hline $\mathrm{Zn}$ & 7 & Sulfato de zinco \\
\hline $\mathrm{Mn}$ & 9 & Sulfato de manganês \\
\hline $\mathrm{Mg}$ & 10 & Sulfato de magnésio \\
\hline
\end{tabular}

Doses e freqüência e aplicações ${ }^{(2)}$

$\mathrm{kg} \mathrm{ha}^{-1}$

10 cultivo: 30,60 e 90 de N; 5o e 70 cultivos: 40, 80 e 120 de N; 10 e e 12 cultivos: 20,40 e 80 de N; 140 e $16^{\circ}$ o cultivos: 80, 120 e 160 de $N$

50, 100 e 150 de $\mathrm{P}_{2} \mathrm{O}_{5}$ nos cultivos $\mathrm{n}$ ㄴ 1, 2, 5, 8, 10 e 14

a partir do 9o cultivo foi convertido em tratamento zero de $K\left(K_{0}\right)$

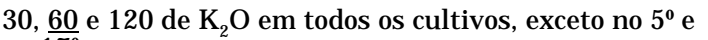
no 17 은

$0, \underline{1}$ e 2 de Cu no $3 \circ, 7^{\circ}$ e $14^{\circ}$ cultivos

$0,2000,4000$ e 6000 (PRNT $=100 \%)$ no 3o cultivo

$0,10,20$ e 30 de $S$ no 5, 10, $12 \circ$ e 14 - cultivos

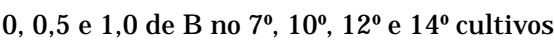

0,5 e 10 de $Z n$ no $7^{\circ}$ e $14^{\circ}$ cultivos

$0,7,5$ e 15 de $M n$ no 9o e 14ํㅜㄴ no $12^{\circ}$ cultivo

$0,5,10$ e 20 de $\mathrm{Mg}$ no $10^{\circ}$ cultivo e $0,20, \underline{40}$ e 60 no $12^{\circ}$ e 14 cultivos

\footnotetext{
(1) Houve mais que um cultivo por ano. ${ }^{(2)}$ Valores sublinhados indicam doses básicas de nutrientes e de calcário aplicados em todos os demais tratamentos. (3) Tratamento incluído para avaliar o efeito da remoção de restos vegetais nas col heitas de cada cultivo de arroz e de soja. Nesses cultivos, os restos vegetais foram retornados somente às parcelas do tratamento "resíduos", após a trilha dos grãos.

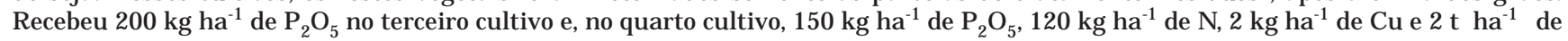
calcário.
} 
de novembro a janeiro e, para soja e caupi, de maio a agosto. A seqüência de culturas evariedades, durante os oito anos de cultivo, desde a derrubada e queima da floresta primária, encontra-se no quadro 2.

O delineamento experimental foi de blocos ao acaso, com quatro repetições. As parcelas eram de $10 \times 5$ m, utilizando-sea parte central de $6 \times 3$ m como área útil para todas as avaliações e amostragens.

No período de floração média de cada cultura, foram tomadas amostras compostas de solo $(0-15 \mathrm{~cm})$ em cada parcela, constituídas de 10 subamostras. Por ocasião da colheita, foram determinados o peso dos restos culturais secos e o de grãos, amostrados para análises químicas.

Quadro 2. Seqüência de cultivos e variedades plantadas durante oito anos consecutivos

\begin{tabular}{cll}
\hline Cultivo & Cultura & Variedade \\
\hline $\mathrm{n}$ o & Arroz & IAC 47 \\
1 & Soja & Tropical \\
2 & Soja & Tropical \\
3 & Caupi & Manaus \\
4 & Milho & BR 5102 \\
5 & Caupi & VITA 3 \\
6 & Milho & BR 5102 \\
7 & Soja & Tropical \\
8 & Caupi & IPEAN V-69 \\
9 & Milho & BR 5102 \\
10 & Caupi & IPEAN V-69 \\
11 & Milho & BR 5102 \\
12 & Caupi & IPEAN V-69 \\
13 & Milho & BR 5102 \\
14 & Caupi & IPEAN V-69 \\
15 & Milho & BR 5110 \\
16 & Caupi & IPEAN V-69 \\
17 & &
\end{tabular}

Para as análises de solo, as extrações de Ca, Mg e Al foram feitas com KCl $1 \mathrm{~mol} \mathrm{~L}^{-1}$; para $\mathrm{K}, \mathrm{P}, \mathrm{Cu}, \mathrm{Mn}$ e Zn, utilizou-se o Mehlich-1. O pH foi determinado em uma suspensão água:solo de 1:2,5, alumínio, por titulação com NaOH; Ca, Mg, Cu, Mn e Zn, por espectrofotometria de absorção atômica; K, por fotometria de chama; P, por colorimetria, usando o método de Murphy \& Riley (1962); C, pelo método de Walkley \& Black (Allison, 1965); e N, por destilação microKjehldal. Análises de grãos e de resíduos vegetais foram efetuadas por digestão com uma mistura de $\mathrm{H}_{2} \mathrm{SO}_{4}$ e $\mathrm{H}_{2} \mathrm{O}_{2}$, determinado-se macro e micronutrientes por meio dos procedimentos utilizados para o solo.

Nos cálculos de rendimento de grãos, a umidade foi ajustada para 13\%. Nas estimativas dos níveis críticos (Figuras 2, 6, 7 e 8), objetivaram-se os rendimentos relativos com base na maior produtividade do cultivo em cada ano dentro dos tratamentos considerados. Análises de variância e de regressão dos dados de produção e de anál ises de solo foram efetuadas por meio do Statistical Analysis System (SAS I nstitute, I nc., 1988).

\section{RESULTADOS E DISCUSSÃO}

\section{Dinâmica das características químicas do solo após a queima}

O efeito fertilizante e corretivo das cinzas é evidenciado pelo aumento de $\mathrm{Ca}, \mathrm{Mg}, \mathrm{K}, \mathrm{Zn}$ e $\mathrm{pH}$ e pela redução de Al trocável e de sua saturação entre amostragens desol o ao tempo zero (condi ções naturais anteriores à queima) e 2,6 meses após a queima (Figura 1). Segundo Smyth \& Bastos (1984), a queima da floresta, no local deste experimento, adicionou ao

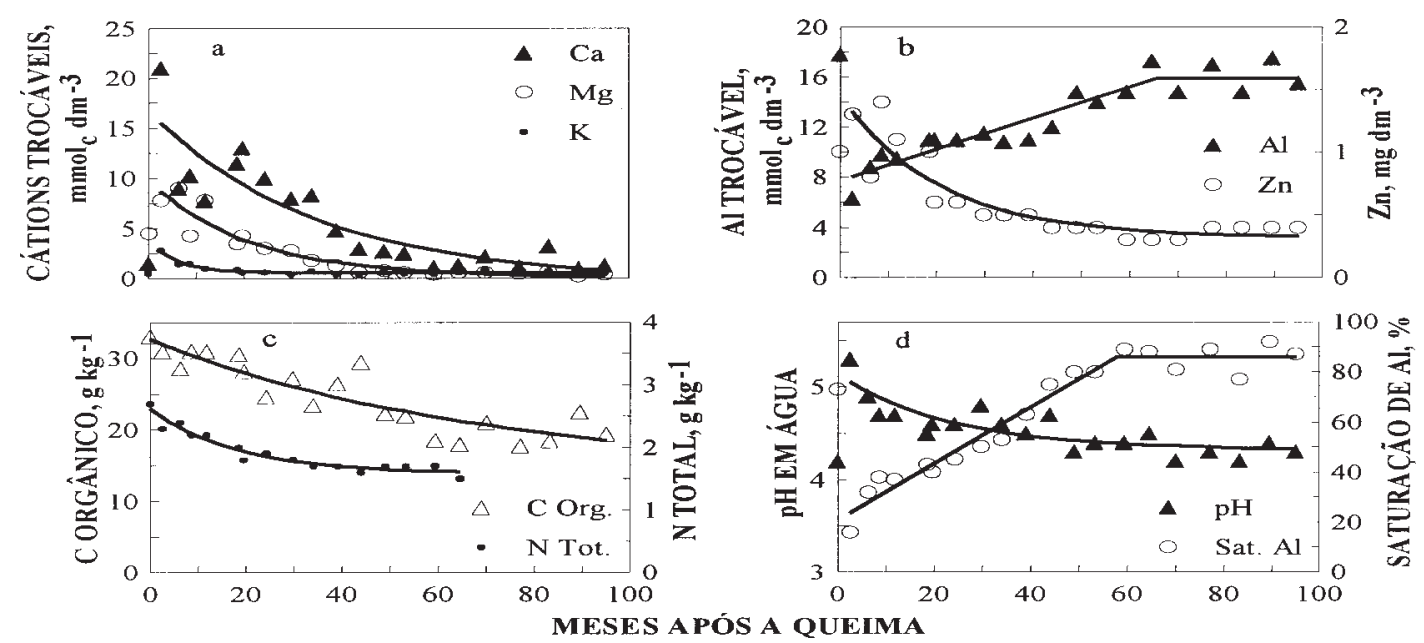

Figura 1. Dinâmica dos teores no solo de Ca, Mg e K trocáveis (a), Al trocável e Zn disponível (Mehlich-1) (b), C orgânico e $\mathbf{N}$ total (c) e, acidez e saturação de Al (d) no período de 100 meses após a queima de uma floresta primária em um latossolo amarelo em Manaus (AM). As análises do solo, antes da derrubada e queima da floresta, são indicadas pelos valores ao tempo de zero meses depois da queima. (As equações ajustadas são apresentadas no Quadro 3). 
solo 9,2 t ha-1 de cinzas, contendo 80; 82; 22; 19; 6; 2; 0,2; 58 e 2,3 kg ha-1 de N, Ca, Mg, K, P, Zn, Cu, Fe e $\mathrm{Mn}$, respectivamente. Todavia, o decréscimo de nutrientes eo aumento deacidez, duranteosubseqüente período de cultivo, demonstraram ser o efeito das cinzas de curta duração. Equações exponenciais e descontínuas usadas para descrever a dinâmica dessas características do solo (Quadro 3) revelaram que os decréscimos de $\mathrm{Ca}$, Mg e K atingiriam $50 \%$ do seus valores máximos aos 23, 15 e 5 meses após a queima, respectivamente. Simultaneamente, obtiveram-se acréscimos lineares até 66 meses após a queima para Al e até 58 meses após a queima para a saturação de Al (Figura 1). Esse decréscimo da fertilidade e o aumento da acidez do sol o, observados neste trabal ho, contribuem para os baixos rendimentos alcançados pelos agricultores, obrigando-os ao desmatamento de novas áreas para os próximos cultivos.

Logo após a queima da floresta, o teor de "P. disponível" (Mehlich-1) no solo foi elevado de 2 para $6 \mathrm{mg} \mathrm{dm}^{-3}$. Em todas as subseqüentes amostragens de solo no tratamento-testemunha, o "P-disponível" oscilou entre 2,5e4,5 mg dm³ (dados nãoapresentados).

A dinâmica dessas características foram semelhantes às observadas em um podzólico na Amazônia peruana, após a queima edurante oito anos de cultivo (Sanchez et al., 1983). Apesar de ambos os solos apresentarem decréscimos em C orgânico, a perda de $25 \%$ durante o primeiro ano de cultivo no podzólico (Peru) foi consi deravelmente superior à taxa de $9,2 \%$ no latossolo (Brasil). Durante os 30 meses iniciais de cultivo, as taxas médias anuais de perda do $\mathrm{N}$ total nesses solos foram similares (17\% para o podzólico e 13\% para o latossolo).

\section{Respostas dos cultivos aos tratamentos}

Observaram-se, com freqüência, aumentos de produtividade de grãos em resposta às aplicações de
P e K, a partir do segundo cultivo, e à aplicação de calcário, a partir do terceiro cultivo, no transcorrer dos 17 cultivos (Quadro 4). As respostas à aplicação de $P$ foram, significativamente, superiores às da testemunha nos 17 cultivos.

Fósforo: Na ausência defertilização fosfatada, após o primeiro cultivo, os rendimentos de grãos foram insignificantes (Figura 2). No primeiro cultivo após a queima, orendimento degrãos de arroz foi aumentado de 1,1 para 2,4 t ha-1, com a aplicação de $50 \mathrm{~kg} \mathrm{ha-1}$ de $\mathrm{P}_{2} \mathrm{O}_{5}$. As produções totais de grãos para os 17 cultivos foram de 1,7, 22,5, 28,7 e 35,2 t ha-1, para os respectivos tratamentos-testemunha e doses acumuladas de 300, 600 e $900 \mathrm{~kg}$ ha-1 de $\mathrm{P}_{2} \mathrm{O}_{5}$. A relação entre a produção de grãos e o "P-disponível" no solo indicou que o nível crítico para milho e soja é de $13 \mathrm{mg} \mathrm{dm}-3$ (Figura 3). Em experimento desenvolvido no mesmo solo, Smyth \& Cravo (1990) encontraram um nível crítico de $P$ para caupi de $8 \mathrm{mg} \mathrm{dm}^{-3}$, para o extrator Mehlich-1, e $12 \mathrm{mg} \mathrm{dm}-3$, para o extrator Bray-1.

Nitrogênio: Os rendimentos das culturas que receberam fertilizante nitrogenado, arroz e milho, são apresentados no quadro 5. Dentro da faixa de 30 a $120 \mathrm{~kg}$ ha-1 deN, não houveaumento de rendimento nos três cultivos iniciais dearroz emilho. Com a diminuição das doses aplicadas no 3ㅇ e 4o cultivos de milho, os rendimentos aumentaram com a dose de $80 \mathrm{~kg} \mathrm{ha-1}$ de N. Essas respostas a diferentes doses de $\mathrm{N}$ evidenciam a necessidade progressiva de maiores doses de N, de 30 a 80 kg ha-1 de N, durante os oito anos de cultivo.

A mineralização do $\mathrm{N}$ orgânico do solo pode ter contribuído para a falta de resposta à adição de $\mathrm{N}$ nos três cultivos iniciais de arroz e milho. A redução de $1 \mathrm{~g} \mathrm{~kg}^{-1}$ de $\mathrm{N}$ total na profundidade de $0-15 \mathrm{~cm}$ do solo, durante os 40 meses iniciais após a queima (Figura 1), corresponde a uma mineralização de 1.500 kg ha-1 de N. A pequena resposta do milho ao $\mathrm{N}$ aplicado pode,

\section{Quadro 3. Equações de regressão ajustadas entre características químicas de um latossolo amarelo de Manaus $(\hat{Y})$ e tempo (t), em meses, após a quei ma da floresta, e esti mativas de tempo para atingir $50 \%$ de redução ou aumento nos valores dessas características}

\begin{tabular}{|c|c|c|c|c|c|}
\hline \multirow{2}{*}{ Características } & \multirow{2}{*}{\multicolumn{2}{|c|}{ E quação }} & \multirow{2}{*}{$\mathbf{R}^{2}$} & \multicolumn{2}{|c|}{ Tempo para $50 \%$} \\
\hline & & & & Redução & Aumento \\
\hline & & & & \multicolumn{2}{|c|}{ Meses } \\
\hline C orgânico, $\mathrm{g} \mathrm{kg}^{-1}$ & $\hat{Y}=13,335+19,233 e^{-0,014 t}$ & & 0,80 & 134 & \\
\hline $\mathrm{N}$ total, $\mathrm{g} \mathrm{kg}^{-1}$ & $\hat{Y}=1,579+1,036 \mathrm{e}^{-0,0546 \mathrm{t}}$ & & 0,94 & (2) & \\
\hline $\mathrm{Ca}, \mathrm{mmol}_{\mathrm{c}} \mathrm{dm}^{-3}$ & $\hat{Y}=-0,286+17,060 \mathrm{e}^{-0,0289 t}$ & & 0,78 & 23 & \\
\hline $\mathrm{Mg}, \mathrm{mmol}_{\mathrm{c}} \mathrm{dm}^{-3}$ & $\hat{Y}=0,072+9,750 \mathrm{e}^{-0,0475 t}$ & & 0,90 & 15 & \\
\hline $\mathrm{K}, \mathrm{mmol}_{\mathrm{c}} \mathrm{dm}^{-3}$ & $\hat{Y}=0,544+3,402 e^{-0,1677 t}$ & & 0,94 & 5 & \\
\hline Al, $\mathrm{mmol}_{\mathrm{c}} \mathrm{dm}^{-3} \quad{ }^{(3)}$ Para $\mathrm{t}<66$ & $\hat{Y}=7,650+0,126 t$ para $t>66 \hat{Y}$ & $=15,9$ & 0,88 & & 33 \\
\hline Saturação de Al, \% ${ }^{(3)}$ Para $t<58$ & $\hat{Y}=20,53+1,1277$ t para $t>58 \hat{Y}$ & $=86$ & 0,96 & & 29 \\
\hline pH em água & $\hat{Y}=4,3161+0,8188 \mathrm{e}^{-0,0425 t}$ & & 0,72 & (2) & \\
\hline $\mathrm{Zn}, \mathrm{mg} \mathrm{dm} \mathrm{m}^{-3}$ & $\hat{Y}=0,3191+1,1397 e^{-0,0493 t}$ & & 0,82 & 21 & \\
\hline
\end{tabular}

(1) Significativos ao nível 5\%. ${ }^{(2)}$ Excede o valor mínimo do modelo. ${ }^{(3)}$ Modelo descontínuo (platô-linear). 
Quadro 4. E feito do manejo de restos culturais e de doses de nutrientes e calcário sobre a produtividade de grãos de 17 cultivos sucessivos de arroz, milho, soja e caupi em latossolo amarelo de Manaus (AM)

\begin{tabular}{|c|c|c|c|c|c|c|c|c|c|c|c|c|c|c|c|c|c|}
\hline \multirow{2}{*}{ Tratamento } & \multicolumn{17}{|c|}{ Cultivo } \\
\hline & 1 & 2 & 3 & 4 & 5 & 6 & 7 & 8 & 9 & 10 & 11 & 12 & 13 & 14 & 15 & 16 & 17 \\
\hline Resíduos $^{(2)}$ & - & $\mathrm{ns}^{(3)}$ & $*$ & $*$ & $*$ & $*$ & $*$ & ns & - & - & - & - & - & - & - & - & - \\
\hline $\mathrm{N}$ & ns & ns & ns & ns & ns & ns & ns & ns & ns & $*$ & ns & $*$ & ns & ns & ns & ns & ns \\
\hline$P$ & ns & $*$ & $*$ & $*$ & $*$ & $*$ & $*$ & ns & $*$ & ns & $*$ & $*$ & $*$ & ns & $*$ & ns & $*$ \\
\hline $\mathrm{K}$ & - & $*$ & $*$ & $*$ & $*$ & ns & $*$ & $*$ & $*$ & $*$ & $*$ & $*$ & $*$ & $*$ & $*$ & $*$ & $*$ \\
\hline $\mathrm{Cu}$ & - & - & ns & ns & ns & ns & ns & ns & ns & $*$ & ns & ns & ns & $*$ & ns & ns & ns \\
\hline Calcário & - & - & $*$ & ns & $*$ & $*$ & $*$ & $*$ & $*$ & $*$ & $*$ & $*$ & $*$ & $*$ & $*$ & $*$ & $*$ \\
\hline $\mathrm{S}$ & - & - & - & - & ns & ns & ns & ns & ns & ns & ns & ns & ns & ns & ns & ns & $*$ \\
\hline$B$ & - & - & - & - & - & - & ns & ns & ns & ns & ns & $*$ & ns & ns & ns & $*$ & ns \\
\hline $\mathrm{Zn}$ & - & - & - & - & - & - & ns & ns & ns & ns & ns & ns & ns & ns & ns & ns & ns \\
\hline $\mathrm{Mn}$ & - & - & - & - & - & - & - & - & ns & ns & ns & $*$ & ns & ns & ns & ns & ns \\
\hline $\mathrm{Mg}$ & - & - & - & - & - & - & - & - & - & ns & ns & $*$ & ns & ns & $*$ & ns & ns \\
\hline
\end{tabular}

(1)Ver Quadro 1 para a espécie e variedade correspondente ao número de cultivo. (2) Produtividade deste tratamento comparado à da testemunha absoluta; este tratamento não mais recebeu $\mathrm{K}$, sendo donominado $\mathrm{K}_{0}$ a partir do nono cultivo. Nos demais tratamentos, foram comparadas diferenças entre doses do nutriente ou cal cário. ${ }^{(3)}$ ns = não significativo ao nível de $5 \%$; * =significativo ao nível $5 \%$.

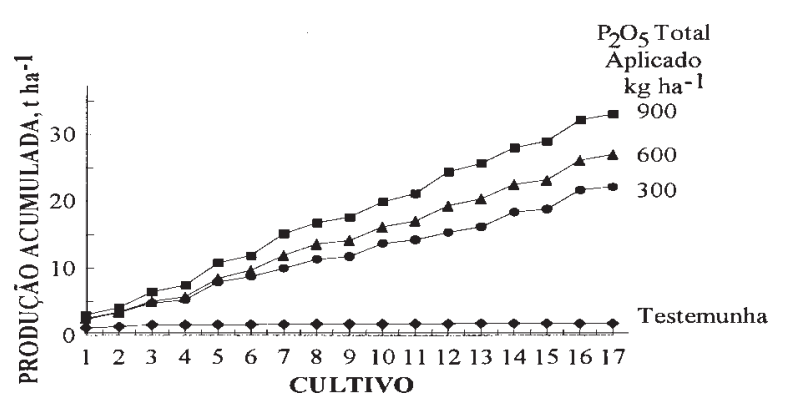

Figura 2. Rendimento acumulado de grãos de 17 cultivos consecutivos no tratamento-testemunha absoluta em comparação com o do tratamento médio de três doses de $P$ aplicadas em um latossolo amarelo em Manaus (AM).

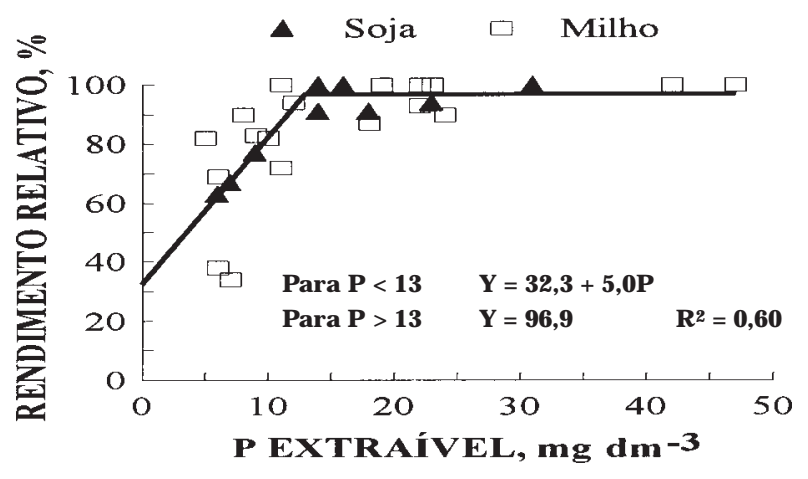

Figura 3. Relação entre rendimentos de três cultivos de soja e seis cultivos de milho em tratamentos com três doses de $\mathbf{P}$ e disponibilidade de $\mathbf{P}$ no solo pelo extrator Mehlich-1. também, estar relacionada com o fato de cada cultivo ter sido antecedido por um, dois e até três cultivos de leguminosas (Quadro2). Estudos realizados no mesmo solo (Smyth et al., 1991) demonstraram que, na média de três anos de cultivo, os resíduos de caupi forneceram às culturas subseqüentes de milho quantidade de $\mathrm{N}$ equival ente ao fornecido por $26 \mathrm{~kg} \mathrm{ha}-1$ de $\mathrm{N}$ na forma de uréia. Outro fator que pode ter contribuído para a baixa resposta do milho ao $\mathrm{N}$ foi $\mathrm{o}$ modo deaplicação do fertilizante. Nesteestudo, as doses foram parceladas em três apl icações iguais: no plantio, aos 25 e 55 dias. Melgar et al. (1991) também observaram que as mel hor es respostas foram obtidas quando toda a dose de $\mathrm{N}$ foi aplicada aos 25 dias ou metade aos 25 e o restante aos 55 dias do plantio.

Potássioe Manejo de Resíduos: Em quatro dos cinco cultivos iniciais, a produção de grãos, com o retorno de resíduos de arroz e de soja, foi igual ou superior à obtida com 30 kg ha-1 de $\mathrm{K}_{2} \mathrm{O}$ (Figura 4). A análise de $\mathrm{K}$ do solo indicou que o retorno de resíduos manteve teores de $\mathrm{K}$ no solo iguais ou superiores aos do tratamento de $60 \mathrm{~kg}$ ha-1 de $_{2} \mathrm{O}$ (Quadro 6). Em geral, para milho e soja, houve aumento de produção até a dose de $60 \mathrm{~kg}$ ha-1 de $\mathrm{K}_{2} \mathrm{O}$, enquanto, para o caupi, essa dose foi de $30 \mathrm{~kg} \mathrm{ha-1}$ de $\mathrm{K}_{2} \mathrm{O}$. Não houve ganhos em rendimento de grãos, por nenhuma cultura, com dose maior do que $60 \mathrm{~kg} \mathrm{ha-1}$ de $\mathrm{K}_{2} \mathrm{O}$. Segundo dados de análise de solo (não apresentados), o decréscimo dos rendimentos com 120 kg ha-1 de $\mathrm{K}_{2} \mathrm{O}$ deveu-se ao efeito antagônico entre K e Mg. Com essa dose de K, a saturação de Mg trocável no sol o diminuiu para menos de $5 \%$ e, de acordo com Malavolta (1980), quando a saturação de $\mathrm{Mg}$ é menor que $10 \%$, as condições são favoráveis ao aparecimento de deficiência de $\mathrm{Mg}$, induzida pelo excesso de K. Neste trabalho, não foi observado aumento do teor de K no solo, durante os 17 cultivos sucessivos (Quadro 6), devendo ser a aplicação de $\mathrm{K}$ nesse solo feita em cada cultivo, de acordo com as exigências das culturas. 


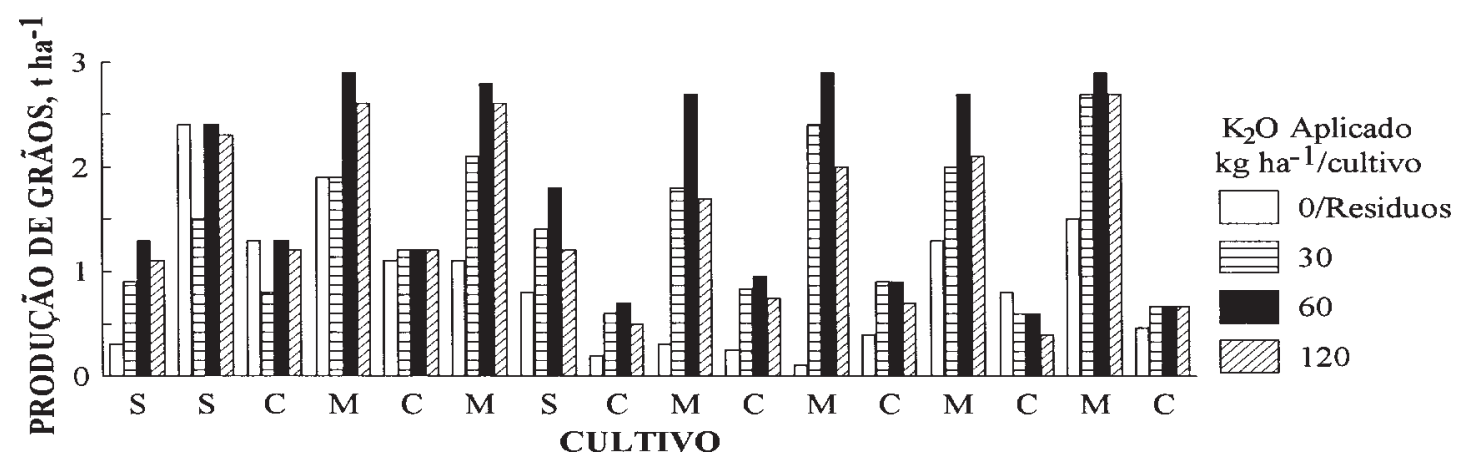

Figura 4. Rendimentos de grãos de 16 cultivos consecutivos de soja (S), milho (M) e caupi (C) em função de três doses de $\mathrm{K}$ e manejo de resíduos de culturas em um latossolo amarelo de Manaus (AM).

Calcário: A magnitude de resposta à calagem dependeu tanto da cultura como do tempo após a aplicação do cal cário (Figura 5). Sem calagem, houve redução no rendimento de grãos de soja entreo 1 으 20 cultivos. Nos quatro cultivos iniciais de milho, não houve aumento significativo em rendimento de grãos para doses maiores que $2 \mathrm{t}$ ha-1 de calcário. Contudo, nos dois cultivos finais de milho, o rendimento com 2 t ha-1 de calcário foi metade do obtido com 4 t ha-1, indicando que o efeito residual de $2 \mathrm{t}$ ha-1 de cal cário, nesse solo, deve ser de 3,5 anos. Dada a queda de rendimentos no tratamento de $2 \mathrm{t}$ ha-1 de cal cário, foi aplicado, durante o quinto cultivo de milho, $1 \mathrm{t}$ ha-1 de calcário nos demais tratamentos (exceto a testemunha), para complementar a aplicação de $2 \mathrm{t}$ ha-1 de cal cário aplicada no primeiro cultivo de milho. Ao contrário do milho, a resposta de caupi à calagem foi mais baixa e nunca excedeu à obtida com a dose de 2 t ha-1, o queé compatível coma conhecida tolerância dessa cultura à acidez do solo (Nicholaides \& Piha, 1987; Wade et al., 1988).

A correlação entre os rendimentos relativos de milho e soja com a saturação deAl no sol o mostrou-se diferente da observada para o caupi. Rendimentos de milho e soja superiores a $80 \%$ do máximo só foram obtidos com saturação deAl inferior a 20\% (Figura 6). Esses resultados concor dam com os de outros estudos realizados nos trópicos (Pearson, 1975; Kamprath, 1980; Sousa et al., 1986; Smyth \& Cravo, 1992), cujos rendimentos atingiram $90 \%$ da produção máxi ma com saturação deAl em torno de 20\%. Para o caupi, Smyth \& Cravo (1992), comparando doses de cal cário e gesso, verificaram que a resposta à calagem estava relacionada mais com o efeito do aumento do teor de cálcio do que com a correção da acidez do solo propriamente dita. Neste estudo, rendimentos de caupi superiores a $90 \%$ do máximo só foram obtidos com saturação de Ca no sol o $>40 \%$ (Figura 7). Neste experimento, verificou-se que $40 \%$ da saturação de Ca correspondeu a 8,7 $\mathrm{mmol}_{\mathrm{C}} \mathrm{dm}^{-3}$ de Ca.

Magnésio: a única resposta significativa à aplicação de Mg ocorreu no 150 cultivo com caupi, onde o rendimento de grãos com 20 ou $40 \mathrm{~kg}$ ha-1 deM g foram superiores ao obtido sem Mg (Quadro 4). Entretanto, a falta de resposta ou o decréscimo de rendimentos com aplicações de $120 \mathrm{~kg} \mathrm{ha}^{-1}$ de K$_{2} \mathrm{O}$ (Figura 4) podem ser atribuídos à possível deficiência de Mg induzida
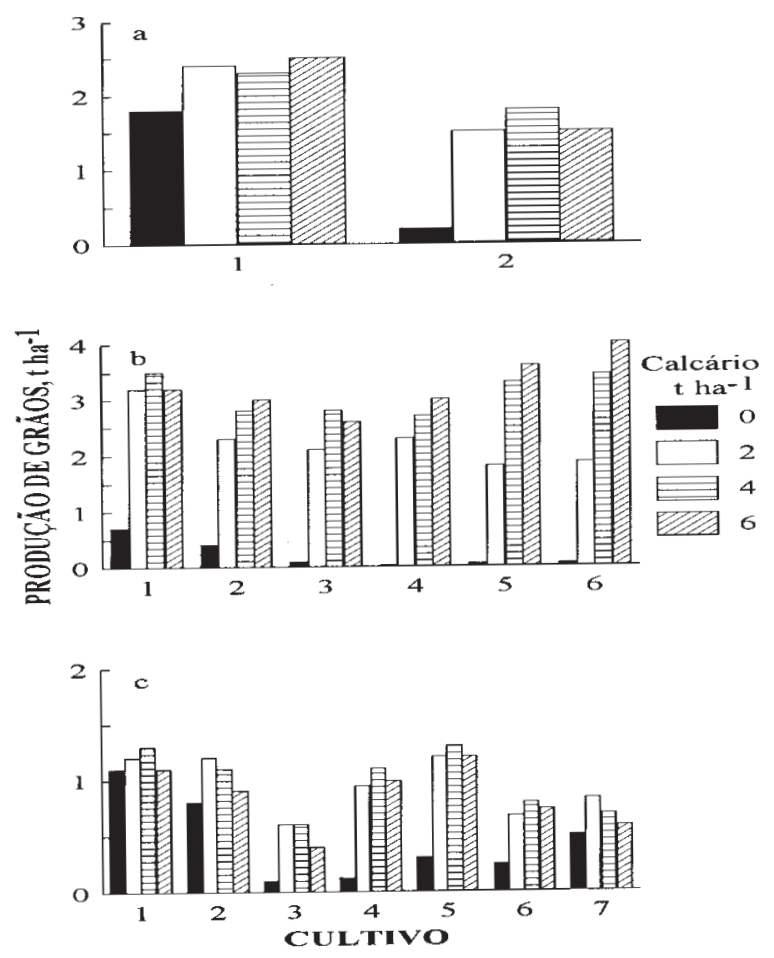

Figura 5. Rendimentos de grãos de soja (a), milho (b) e caupi (c) em função de doses de calcário aplicadas antes do plantio de soja em um latossolo amarelo de Manaus (AM).

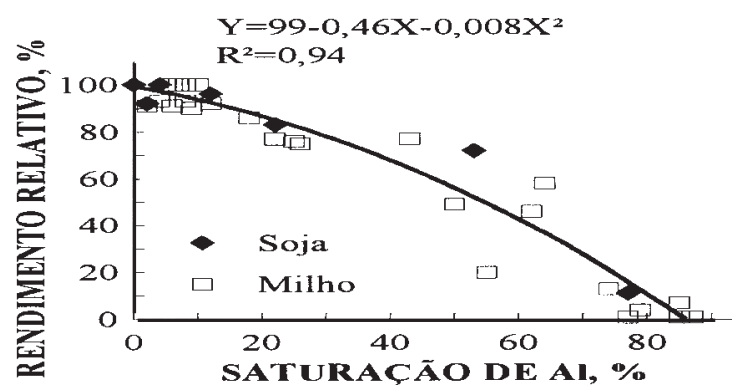

Figura 6. Relacionamento entre rendimento de grãos de oito cultivos de soja e de milho e saturação de Al em quatro doses de calcário, em um latossolo amarelo de Manaus (AM). 
Quadro 5. Produções de grãos de um cultivo de arroz e seis cultivos de milho em função de doses de $\mathbf{N}$ aplicadas durante oito anos de cultivo em um latossolo amarelo de Manaus (AM)

\begin{tabular}{cccccccc}
\hline & & \multicolumn{8}{c}{ Cultivos de milho } \\
\cline { 3 - 8 } Aplicado & Arroz & $\mathbf{1 0}$ & $\mathbf{2 0}$ & 3o & $\mathbf{4 0}$ & $\mathbf{5 0}$ & $\mathbf{6 0}$ \\
\hline kg ha $^{-1}$ & & \multicolumn{7}{c}{ t ha $^{-1}$} \\
20 & - & - & - & 1,5 & 1,5 & - & - \\
30 & 2,9 & - & - & - & - & - & - \\
40 & - & 2,7 & 2,2 & 1,7 & 1,7 & - & - \\
60 & 3,0 & - & - & - & - & - & - \\
80 & - & 2,5 & 1,8 & 2,7 & 2,2 & 2,0 & 2,8 \\
90 & 2,1 & - & - & - & - & - & - \\
120 & - & 2,9 & 2,3 & - & - & 2,2 & 3,1 \\
160 & - & - & - & - & - & 2,0 & 3,2 \\
DMS 0,05 & $\mathrm{ns}^{(1)}$ & $\mathrm{ns}$ & $\mathrm{ns}$ & 0,6 & 0,7 & $\mathrm{~ns}$ & $\mathrm{~ns}$ \\
\hline
\end{tabular}

(1) ns = não significativo ao nível de $5 \%$.

Quadro 6. Teores de K em latossolo amarelo de Manaus (AM) para tratamentos de retorno de resíduos de arroz e soja para a área e aplicação de fertilizante potássico durante 16 cultivos

\begin{tabular}{|c|c|c|c|c|c|c|}
\hline \multirow{2}{*}{ Cultivo } & \multirow{2}{*}{ Espécie } & \multicolumn{4}{|c|}{ Tratamento (kg ha ${ }^{-1}$ de $\left.K_{2} O\right)$} & \multirow{2}{*}{ DMS 0,05 } \\
\hline & & Resíduos-K $K_{0}^{(1)}$ & 30 & 60 & 120 & \\
\hline $\mathrm{n}$ 은 & & \multicolumn{4}{|c|}{$\ldots \mathrm{K}$ no solo, $\mathrm{mg} \mathrm{dm}^{-3}$} & \\
\hline 2 & Soja & 124 & 61 & 91 & 78 & 40 \\
\hline 3 & Soja & 32 & 20 & 26 & 30 & ns \\
\hline 4 & Caupi & 52 & 29 & 48 & 68 & 12 \\
\hline 5 & Milho' & 24 & 16 & 19 & 19 & ns \\
\hline 6 & Caupi & 50 & 34 & 50 & 97 & 15 \\
\hline 7 & Milho & 21 & 18 & 25 & 64 & 11 \\
\hline 8 & Soja & 25 & 23 & 48 & 110 & 15 \\
\hline 9 & Caupi & 38 & 38 & 77 & 154 & 19 \\
\hline 10 & Milho & 30 & 26 & 44 & 81 & 11 \\
\hline 11 & Caupi & 23 & 31 & 70 & 119 & 24 \\
\hline 12 & Milho & 28 & 31 & 50 & 118 & 13 \\
\hline 13 & Caupi & 42 & 48 & 98 & 120 & 20 \\
\hline 14 & Milho & 24 & 28 & 44 & 83 & 12 \\
\hline 15 & Caupi & 27 & 41 & 63 & 89 & 14 \\
\hline 16 & Milho & 19 & 22 & 25 & 34 & 13 \\
\hline 17 & Caupi $^{(2)}$ & 16 & 21 & 28 & 34 & 11 \\
\hline
\end{tabular}

(1) Tratamento com retorno dos resíduos vegetais das culturas de soja após a col heita. ${ }^{(2)}$ Cultivos que não receberam aplicações de fertilizante potássico.

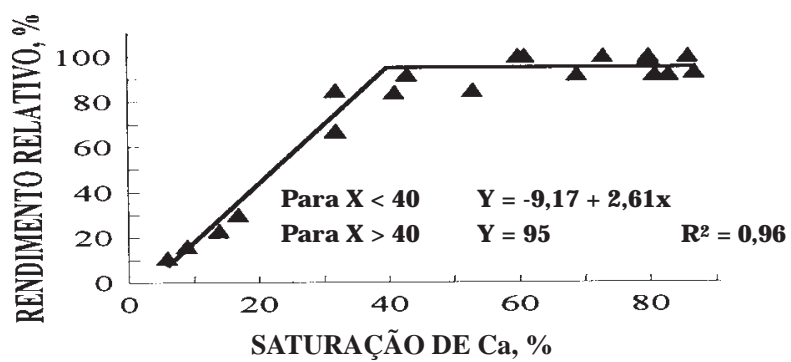

Figura 7. Relacionamento entre rendimento de grãos de sete cultivos de caupi e saturação de Ca em quatro doses de calcário em um latossolo amarelo de Manaus (AM). por excesso de K no solo. Quando os rendimentos de caupi nos tratamentos de $\mathrm{Mg}$ foram avaliados em conjunto com a dose máxima de K, identificou-se o valor de $6,1 \%$ de saturação de Mg como critério diagnóstico desse elemento, nos quatro últimos cultivos de caupi (Figura 8). Relações semelhantes entre rendimento de grãos e índices de $\mathrm{Mg}$ no solo, durante os quatro cultivos finais de milho, não foram significativas.

A aplicação de cal cário cal cítico com 0,96\% de MgO, aos 18,5 meses após a queima, causou forte redução da saturação de Mg no solo que, eventualmente, atingiu o nível crítico de $6,1 \%$, para o caupi, durante o 11을 cultivo (Figura 9). A aplicação de $40 \mathrm{~kg} \mathrm{ha}^{-1}$ de Mg, no último cultivo de caupi, corrigiu essa deficiência. Tais resultados indicam que, mesmo na ausência de el evadas doses de K, houve limitações de Mg a partir de 60 meses após a queima.

Enxofreemicronutrientes: Diferenças significativas aos tratamentos de $\mathrm{S}$ e de micronutrientes foram esporádicas durante a seqüência de cultivos (Quadro 4). Tais efeitos estavam associados a decréscimos de produtividade por excesso do nutriente, e não por acréscimos.

\section{Comparações com estudos em podzólicos da amazônia peruana}

As limitações nutricionais identificadas durante oito anos de cultivo no latossolo amarelo são comparadas com as de Sanchez et al. (1983) em um podzól ico vermel ho-amarel o álico de textura arenosa/ média, em Yurimaguas, Peru (Quadro 7). Todas as limitações nutricionais, no podzólico, ocorreram com menor tempo de cultivo após a derrubada e queima da floresta, com exceção do P, que estava sujeito à maior capacidade de fixação no latossolo de textura muito argilosa. É possível que a precocidade no aparecimento da deficiência de $\mathrm{N}$ no podzólico esteja relacionada com a menor freqüência de plantio de leguminosas nesse solo. Durante os oito anos de cultivo, a relação média entre o plantio de gramíneas e leguminosas em Yurimaguas e Manaus foi de 3,2 e 1,7 , respectivamente.

As produtividades obtidas nolatossol o de Manaus e no podzólico de Yurimaguas, durante oito anos de cultivo, encontram-se no quadro 8. Para tais

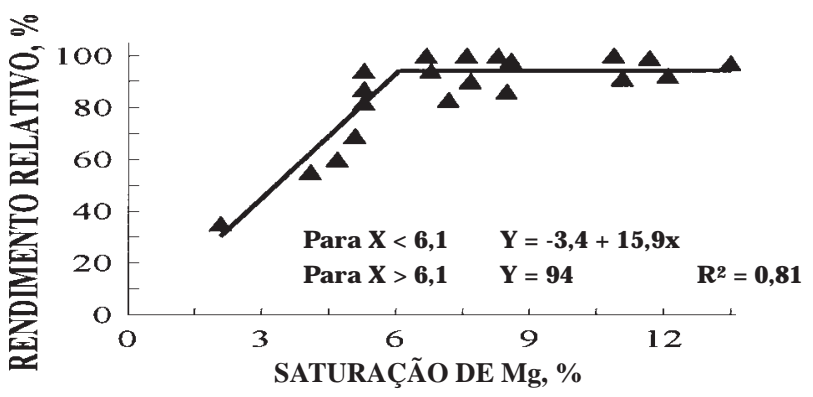

Figura 8. Relacionamento entre rendimento de grãos de quatro cultivos de caupi e saturação de Mg em tratamentos com quatro doses de Mg ea dose máxi ma de K, aplicadas em um latossolo amarelo de Manaus (AM). 
Quadro 7. Cronologia de aparecimento de limitações nutricionais, durante oito anos de cultivo, em latossolo amarelo álico (LAa) de textura muito argilosa em Manaus (AM) e podzólico vermelhoamarelo álico (PVa) de textura arenosa/média em Yurimaguas (Peru)

\begin{tabular}{lcc}
\hline \multirow{2}{*}{ Limitação Nutricional } & \multicolumn{2}{c}{ Meses após a queima da floresta } \\
\cline { 2 - 3 } & LAa & PVa $^{(\mathbf{1})}$ \\
\hline N & 37 & 6 \\
P & 1 & 10 \\
K & 9 & 4 \\
Acidez & 18 & 1 \\
Mg & 60 & 12 \\
S & - & 6 \\
B & - & 6 \\
Cu & - & 1 \\
Mn & - & 38 \\
Zn & - & 40 \\
\hline
\end{tabular}

(1) Fonte: Sanchez et al. (1983).

comparações, usaram-se as produções obtidas no tratamento de 4 t ha-1 de calcário em Manaus, e no tratamento que recebeu fertilizantes e calcário, em Yurimaguas. Observaram-se produtividades médias dearroz, milho esoja bastante semel hantes em ambos os ecossistemas. A maior produtividade total de grãos durante oito anos de cultivo no podzólico deveu-se, principalmente, ao maior número de cultivos e à ausência de plantios de caupi. Apesar desemelhantes capacidades produtivas em ambos os sistemas, essas comparações entre Manaus eYurimaguas mostraram que a seqüência e a correção de deficiências nutricionais seriam particulares a cada local.

A produção de grãos no primeiro ano de cultivo no tratamento-testemunha do latossolo amarelo foi de 1,1 t ha-1 de arroz, seguida de 0,2 t ha-1 de soja. Com esse declínio de produtividade no sistema itinerante, seria necessária a abertura de novas áreas de floresta para o cultivo. Sob condições adequadas de adubação e calagem, obteve-se uma média anual de 4,1 t ha-1 de grãos (Quadro 8), que corresponde à produção de, aproximadamente, 3 ha do sistema itinerante. Com base nessas comparações, seria necessário cultivar quase 24 ha nosistema itinerante, em 8 anos, para conseguir o total de grãos produzi dos em 1 ha com manejo adequado defertilizantes e cal cário, no mesmo período.

Exportações de N e Mg, superiores ao aplicado, são indicativos da necessidade de maior aporte desses nutrientes para prolongar o período decultivo (Quadro 9). A remoção de $P$, equivalente a $56 \%$ do $P$ total aplicado, indica eficiência de uso pelo sistema de cultivo e manejo utilizados neste estudo. O superávit de $K$ no solo também confirma a baixa eficiência de uso desse nutriente e sua suscetibilidade à lixiviação nos latossol os do trópico úmido.

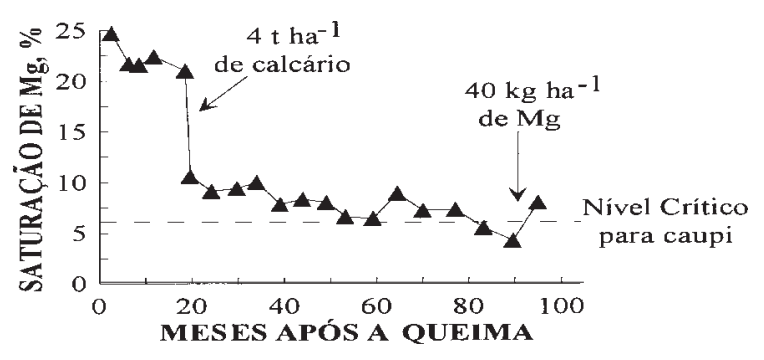

Figura 9. Dinâmica da saturação de Mg do solo no tratamento de 4 t ha-1 de calcário e $60 \mathrm{~kg} \mathrm{ha}^{-1}$ de $\mathrm{K}_{2} \mathrm{O}$ em um latossolo amarelo de Manaus (AM).

Quadro 8. Produtividade total e média de arroz, milho, soja e caupi durante oito anos de cultivo e manejo adequado de fertilizantes e calcário em latossolo amarelo de Manaus (AM) e em podzólico vermelho-amarelo de Yurimaguas (Peru)

\begin{tabular}{|c|c|c|c|c|c|c|}
\hline \multirow{2}{*}{ Cultura } & \multicolumn{3}{|c|}{ Latossolo-amarelo } & \multicolumn{3}{|c|}{ Podzólico vermelho-amarelo } \\
\hline & Cultivos & Total & Média & Cultivos & Total & Média \\
\hline & $\mathrm{n}$ o & \multicolumn{2}{|c|}{$-\mathrm{t} \mathrm{ha}^{-1}-$} & $\mathrm{n}$ o & \multicolumn{2}{|c|}{$-\mathrm{t} \mathrm{ha}^{-1}$} \\
\hline Arroz & 1 & 1,8 & 1,8 & 6 & 13,6 & 2,3 \\
\hline Milho & 6 & 18,6 & 3,1 & 7 & 19,3 & 2,8 \\
\hline Soja & 3 & 5,3 & 1,8 & 6 & 11,1 & 1,9 \\
\hline Caupi & 7 & 6,8 & 1,0 & - & - & - \\
\hline Total & 17 & 32,5 & & 19 & 44,0 & \\
\hline
\end{tabular}

(1) Fonte: Alegre et al. (1991).

Quadro 9. Balanço entre quantidades de N, P, K, Ca e Mg adicionadas e exportadas na colheita de grãos de 17 cultivos no tratamento de $4 \mathrm{t} \mathrm{ha}^{-1} \mathrm{de}$ calcário em latossolo amarelo de Manaus (AM)

\begin{tabular}{cccc}
\hline \multirow{2}{*}{ Nutriente } & \multicolumn{2}{c}{ Adicionado } & \multirow{2}{*}{ Exportado } \\
\cline { 2 - 3 } & Por ano & Total & \\
\hline & & $\mathrm{kg} \mathrm{ha}^{-1}$ & \\
$\mathrm{~N}$ & 79 & 634 & 1014 \\
$\mathrm{P}$ & 33 & 264 & 148 \\
$\mathrm{~K}$ & 75 & 600 & 379 \\
$\mathrm{Ca}$ & 205 & 1640 & 92 \\
$\mathrm{Mg}$ & 9 & 72 & 88 \\
\hline
\end{tabular}

\section{CONCLUSÕES}

1. A ordem de ocorrência delimitações nutricionais ao cultivo contínuo, durante oito anos após o desmatamento e queima da vegetação de floresta equatorial úmida, em latossolo amarelo álico muito argiloso, foi de $\mathrm{P}$, seguido de $\mathrm{K}$, acidez, $\mathrm{N}$ e Mg. 
2. Aplicações de uma dose média anual de 33,75 , 500,9 e 0,4 kg ha-1 de P, K, calcário (PRNT $=100 \%$ ), $\mathrm{N}, \mathrm{Mg}$ (contido no calcário) e $\mathrm{Cu}$, respectivamente, permitiram a manutenção de uma produtividade, na mesma área, durante oito anos, três vezes maior do que a obtida no primeiro ano de cultivo em condições semel hantes às do sistema itinerante.

3. O sistema de cultivo contínuo na mesma área, com uso criterioso de adubação e de calagem, oferece vantagens de aumento de produtividade eredução da necessidade do desflorestamento na Amazônia.

\section{LITE RATURA CITADA}

ALEGRE, J .C.; SANCHEZ, P.A. \& SMYTH, T.J . Manejo de suelos con cultivos continuos en los trópicos humedos del Peru. In SMYTH, T.J .; RAUN, W.R. \& BERTSCH, F., eds. Manejo de suel os tropicales en Latinoamerica. Raleigh, North Carolina State University, 1991. p.157-168.

ALLISON, L.E. Organic carbon. In: BLACK, C.A.; EVANS, D.D.; WHITE, J.L.; ENSMINGER, L.E. \& CLARK, F.E., eds. Methods of soil analysis. Part 2. Madison, American Society of Agronomy, 1965. p.1367-1378.

COCHRANE, T.T. \& SANCHEZ, P.A. Land resources, soils properties and their management in the Amazon region: $A$ state of knowledge report. In: HECHT, S.B., ed. Amazon land use research. Cali, CIAT, 1982. p.138-209.

CUNHA, R.P. Deforestation estimates through remote sensing: the state of the art in the legal Amazon. In: SYMPOSIUM Amazônia: facts, problems and solutions. Annals. São Paulo, University of São Paulo, 1989. p.240-273.

EMBRAPA - Empresa Brasileira de Pesquisa Agropecuária. Boletim Agrometeorológico. Manaus, EMBRAPA - UEPAE, 1984. n.p. (Boletim Agrometeorológico, 6)

FEARNSIDE, P.M. Deforestation in Brazilian Amazônia. In: WOODWE LL, G.M., ed. The earth in transition: paterns and process of impoverishment. New York, Cambridge University Press, 1990. p.211-238.

KAMPRATH, E.J. Soil acidity in well-drained soils of the tropics as a constraint to food production. In: DROSDOFF, M.; ZANDSTA, H. \& ROCKWOOD, W.G., eds. Priorities for alleviating soil - related constraints to food production in the tropics. Los Baños, IRRI, 1980. p.171-187.

MAHAR, D.J . Government policies and deforestation in Brazil's Amazon region. Washington, World Bank, 1989. 56p.

MALAVOLTA, E. Elementos de nutrição mineral de plantas. Piracicaba, Ceres, 1980. 251p.

MELGAR, R.J .; SMYTH, T.J .; CRAVO, M.S. \& SANCHEZ, P.A. Doses e épocas de aplicação de fertilizante nitrogenado para milho em latossolo amarelo da Amazônia Central. R. bras. Ci. Solo, Campinas, 15:289-296, 1991.
MURPHY, J. \& RILEY, J.R. A modified single solution method for the determination of phosphate in natural waters. Anal. Chim. Acta, Amsterdam, 27:31-36, 1962.

NICHOLAIDES, J.J . \& PIHA, M.I. A new methodology to select cultivars tolerant to $\mathrm{Al}$ and with high yield potential. In: workshop on evaluating sorghum for tolerance to Al - toxic tropical soils in Latin America, Cali, 1984. Proceedings Cali, CIAT, 1987. p.103-116.

PEARSON, R.W. Soil acidity and liming in the humid tropics. Ithaca, Cornell University, 1975. (Cornell Int. Agric. Bull, 30)

RADAMBRASIL - Ministério das Minas e Energia. Dep. Nac. de Prod. Mineral. Fol ha SA-21 - Santarém. Rio de J aneiro, Projeto RADAMBRASI L, Lev. de Rec. Nat., 1975. v.101. 510p.

RODRIGUES, T.E.; REIS, R.S.; MORIKAWA, I.K.; FALESI, I.C. \& SILVA, B.N.R. Levantamento detalhado dos solos do IPEAAOc. DNPEA- Instituto de Pesquisa e Experimentação da Amazônia Ocidental (IPEAAOc), 1972. 63p. (Boletim Técnico, 1)

SANCHEZ, P.A. \& SALINAS, J.G. Low-input technology for managing Oxisols and Ultisols in Tropical America. Adv. Agron., Madison, 34:281-283, 1981.

SANCHEZ, P.A.; VILLACHICA, J.H. \& BANDY, D.E. Soil fertility dynamics after clearing a tropical rainforest in Peru. Soil Sci. Soc. Am. J., Madison, 47:1171-1178, 1983.

SAS INSTITUTE. SAS/STAT user's guide release: 6.03 edition. Cary, North Carolina, 1988, 1028p.

SMYTH, T.J . \& BASTOS, J.B. Alterações na fertilidade de um latossolo amarelo álico pela queima da vegetação. $R$. bras. Ci. Solo, Campinas, 8:127-132, 1984.

SMYTH, T.J . \& CRAVO, M.S. Critical phosphorus levels for corn and cowpea in a Brazilian Amazon Oxisol. Agron.J ., Madison, 82:309-312, 1990

SMYTH, T.J . \& CRAVO, M.S. Aluminum and calcium constraints to continuous crop production in a Brazilian Amazon Oxisol. Agron. J., Madison, 84:834-850, 1992.

SMYTH, T.J .; CRAVO, M.S. \& MELGAR, R.J. Nitrogen supplied to corn by legumes in a Central Amazon Oxisol. Trop. Agric., Trinidad, 68:366-372, 1991.

SOUSA, D.M.G.; CARVALHO, L.J.C. \& MIRANDA, L.N. Correção da acidez do sol o. In: GOEDERT, W.J . ed. Solos dos Cerrados: Tecnol ogias e estratégias de manejo. São Paulo, N obel, 1986. p.99-127.

WADE, M.K.; GILL, D.W.; SUBAGJ O, H.; SIDJ ADI, M. \& SANCHEZ, P.A. Overcoming soil fertility constraints in a transmigration area of Indonesia. Raleigh, North Carolina State University, 1988, 60p. (TROPSOILS Bull. 88-0I) 